\title{
Quality of life among parents of preterm infants: a scoping review
}

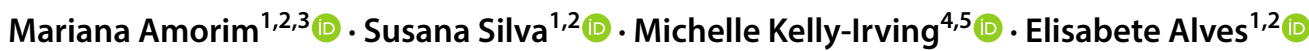

Accepted: 12 December 2017

c) Springer International Publishing AG, part of Springer Nature 2017

\begin{abstract}
Purpose To synthesize the body of knowledge on the factors influencing the QoL of mothers and fathers of preterm infants. Methods A scoping review was performed. Publications indexed in PubMed®, Web of Science ${ }^{\text {TM }}$, CINAHL ${ }^{\circledR}$ and PsyCINFO ${ }^{\circledR}$ were searched, targeting studies presenting original empirical data that examined parental perception on QoL after a preterm delivery. Eligibility and data extraction were conducted by two independent researchers. The main quantitative findings were synthesized and qualitative data were explored by content analysis.

Results The studies, 11 quantitative and 1 mixed methods, were derived mainly from the USA $(n=6)$. Heterogeneity across the studies was observed regarding the operationalization of QoL and the use of units of analysis (mothers, parents, families and caregivers). In a context where 40 out of 45 covariates were analysed by only one or two studies, results suggested that parental QoL after a preterm delivery is influenced by factors related with mother's characteristics, family issues and health care environment rather than infants' variables. Factors regarding fathers' characteristics and structural levels were not addressed.

Conclusions Standardizing the operationalization of the QoL when analysing mothers and fathers of preterm infants calls for a structured questionnaire adapted to their specific needs. Further research should include both mothers and fathers, invest in mixed methods approaches and be performed in different countries and settings for allowing integration and comparison of findings.
\end{abstract}

Keywords Quality of life $\cdot$ Premature birth $\cdot$ Parents $\cdot$ Family-integrated care $\cdot$ Scoping review

\section{Introduction}

Preterm birth, occurring before completing 37 gestational weeks [1], constitutes the leading cause of neonatal mortality and morbidity worldwide [2]. The increased preterm birth rates and the higher survival chances of these infants, consistently reported over the last three decades [3], have

Mariana Amorim

mariana.amorim@ispup.up.pt

1 EPIUnit - Instituto de Saúde Pública, Universidade do Porto, Rua das Taipas $n^{\circ} 135,4050-600$ Porto, Portugal

2 Departamento de Ciências da Saúde Pública e Forenses e Educação Médica, Faculdade de Medicina, Universidade do Porto, Al. Prof. Hernâni Monteiro, 4200-319 Porto, Portugal

3 Global Public Health Doctoral Programme, Porto, Portugal

4 INSERM UMR1027, 31000 Toulouse, France

5 Université Toulouse III Paul Sabatier, UMR1027, 31000 Toulouse, France justified the increasing number of studies concerning health and quality of life (QoL) of children and adults born preterm [4-6]. These studies aim to develop optimal evidencebased effective perinatal intensive care [7] and to standardize approaches to the organization of care and medical interventions [8]. Recent studies point to the need to also acknowledge parents' experiences and views focused on developing family-integrated neonatal services $[9,10]$. Nevertheless, the factors influencing parental QoL during and after preterm infants' hospitalization in Neonatal Intensive Care Unit (NICU) have not been systematized.

A preterm birth affects the family environment not only during the infant's hospitalization in NICU, but for many years [11]. Mothers and fathers of preterm infants revealed an increased risk of developing parental stress [12-14], depressive symptoms and anxiety shortly after delivery $[15,16]$, as well as poorer family functioning and higher family burden several years after birth, when compared with families of full-term infants [17]. Existing literature reviews provide information about parental mental health 
and stress, and identify the effects of a preterm delivery on the family structure, with a specific focus on parents of very or extremely low birth weight infants [18], with or without neuropsychomotor disturbance [19]. These reviews were not performed with a systematic methodology neither focused on the factors influencing QoL of mothers and fathers of preterm infants, defined as the individuals' perception of their own physical, psychological, social and environmental wellbeing, taking into account their culture and value systems, goals and expectations [20]. Such systematic knowledge could represent a relevant tool for designing and developing sustainable and effective family-centred and integrated health care when parenting a preterm infant. Moreover, the evidence provided would contribute to enrich medical practices thus improving health governance in the context of prematurity.

This scoping review aims to synthesize the body of knowledge on the factors influencing the QoL of mothers and fathers of preterm infants.

\section{Methods}

We followed the guidance for descriptive systematic scoping reviews by Levac et al. [21], based on the methodological framework developed by Arksey and O’Malley [22].

\section{Stage 1: Identifying the research question}

The central question guiding this scoping review is the following one: What are the main factors influencing the $\mathrm{QoL}$ of mothers and fathers of preterm infants?

\section{Stage 2: Identifying relevant studies}

A search of the publications on four electronic databases (PubMed ${ }^{\circledR}$, Web of Science ${ }^{\mathrm{TM}}$, CINAHL $®$ and PsycINFO ${ }^{\circledR}$ ) was undertaken in July 2017, with no restriction set for language or time of publication, using the following search expression: ("QoL" OR "quality of life" OR "life quality" OR "life qualities") AND ("mother" OR "father" OR "mothers" OR "fathers" OR "parent" OR "parents" OR "family" OR "families" OR "maternal" OR "paternal" OR "parental") AND ("birth, premature" OR "births, premature" OR "premature births" OR "preterm birth" OR "birth, preterm" OR "births, preterm" OR "preterm births" OR "infants, premature" OR "premature infant" OR "preterm infants" OR "infant, preterm" OR "infants, preterm" OR "preterm infant" OR "premature infants" OR "neonatal prematurity" OR "prematurity, neonatal"). The search was followed by backward reference tracking, examining the references of the selected publications based on full-text assessment.

\section{Stage 3: Study selection}

The inclusion criteria allowed only empirical, peerreviewed, original full-length studies that explored the QoL of mothers and/or fathers of preterm infants as their main outcome. The exclusion criteria disallowed studies focusing on the QoL of infants, adolescents or adults born prematurely, studies with data about parents' QoL only during pregnancy and studies in which the infants' gestational age was above 37 weeks.

The first and the last authors (M.A. and E.A.) independently screened all the papers retrieved initially, based on the title and abstract and afterwards, based on the full-text. This was crosschecked in both phases. The study selection was guided by the research question and inclusion and exclusion criteria. An almost perfect strength of agreement was achieved in both phases (total percentage of agreement $=96.5 \%$; Cohen's kappa $=0.91,95 \%$ CI 0.87-0.96). Disagreement was solved by joint discussion until consensus could be reached or, when consensus was not achieved, by the assessment of the second author (S.S.), based on the same criteria defined for study selection.

The screening process is summarized in Fig. 1. The titles of 575 records were retrieved. After the removal of the duplicates, 405 records were examined. Based on title and abstract assessments, 385 records were excluded, mainly because they were neither original full-length peerreview studies nor explored parental QoL as the main outcome. Of the 20 fully read papers, 10 met the inclusion criteria. After the backward reference tracking, two papers were included and the final scoping review was composed by 12 papers.

\section{Stage 4: Charting the data}

A standardized data extraction sheet was developed and completed by two independent researchers (M.A. and E.A.). Descriptive data for the characterization of studies included research design; information about the authors and publication year; country where the study was developed; study aim; participants and sample; and instruments used to assess parental QoL.

We retrieved quantitative data on variables whose association with parental QoL was statistically significant and the directions of the associations were registered. All the remaining variables whose association with QoL of parents of preterm infants was tested and reported were also extracted. 
Fig. 1 Flowchart showing the search results and screening process for the scoping review on QoL of parents of preterm infants

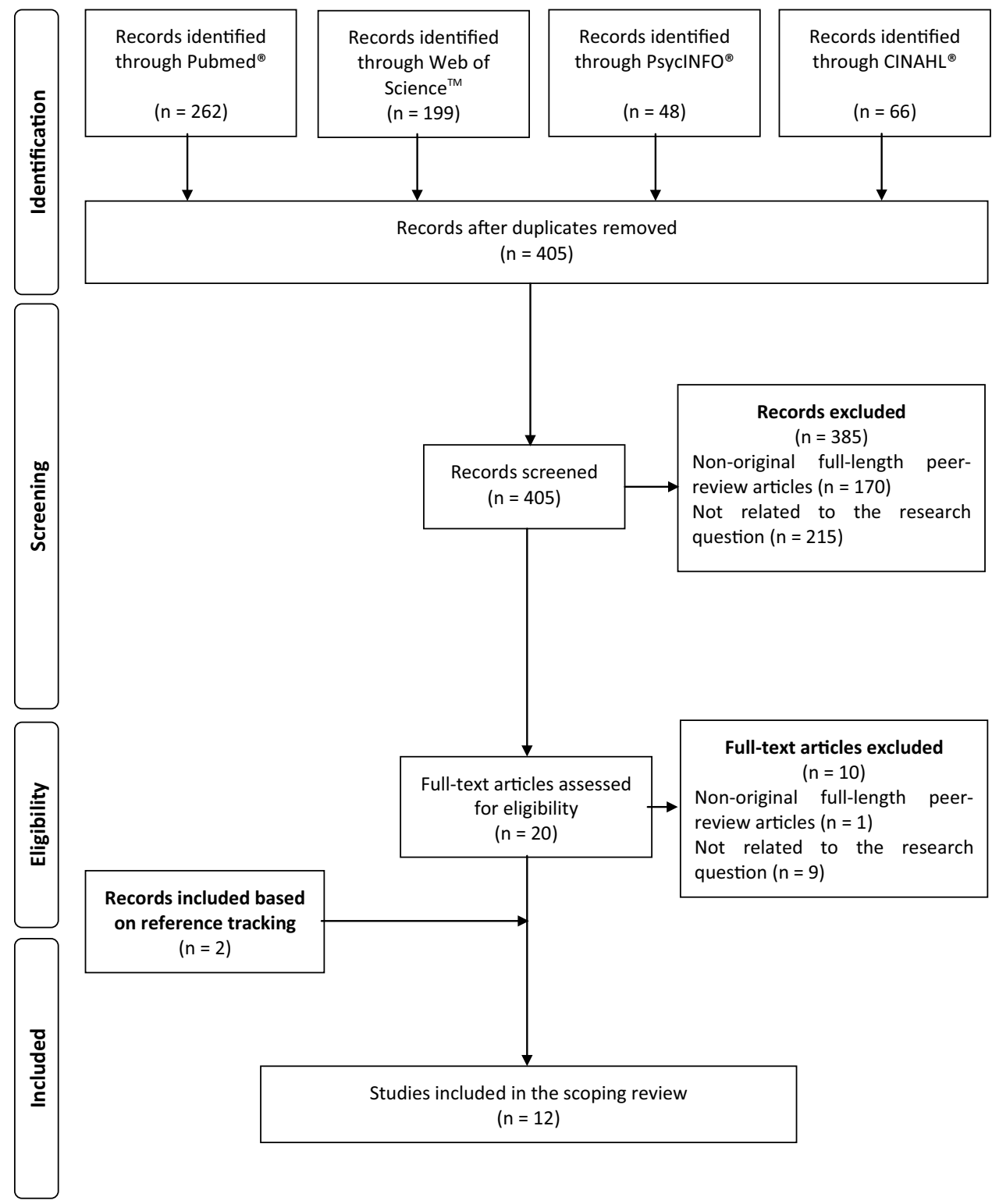

The qualitative data presented in only one study [23] were analysed according to the protocol for content analysis developed by Stemler [24]. In each of the main themes identified by the authors of the above-mentioned study, we selected the categories with the highest and the lowest difference between the two interviewed groups (families of infants with cerebral palsy or hydrocephalus and families of neurologically normal infants). Additionally, the most frequently reported categories related with positive and negative impacts of a preterm birth on family QoL were retrieved.

\section{Stage 5: Collating, summarizing and reporting the results}

The main characteristics of the 12 studies included can be and ordered by the year of publication.

The factors influencing the QoL of mothers and fathers of preterm infants were identified and then grouped into issues related with mother, infant, family and health care (Table 2). The main findings are presented in Table 3. found in Table 1. Studies were grouped by research design 


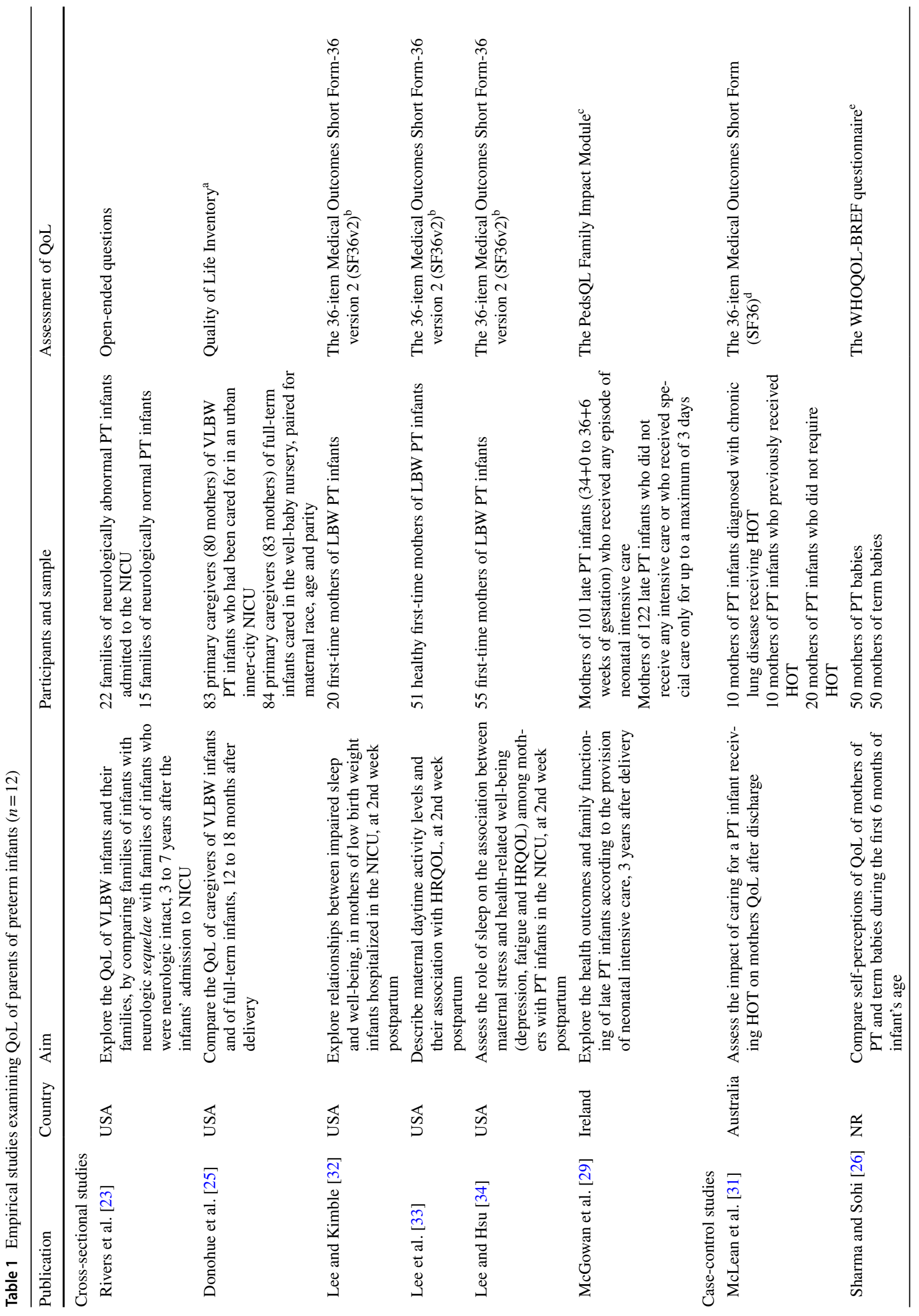




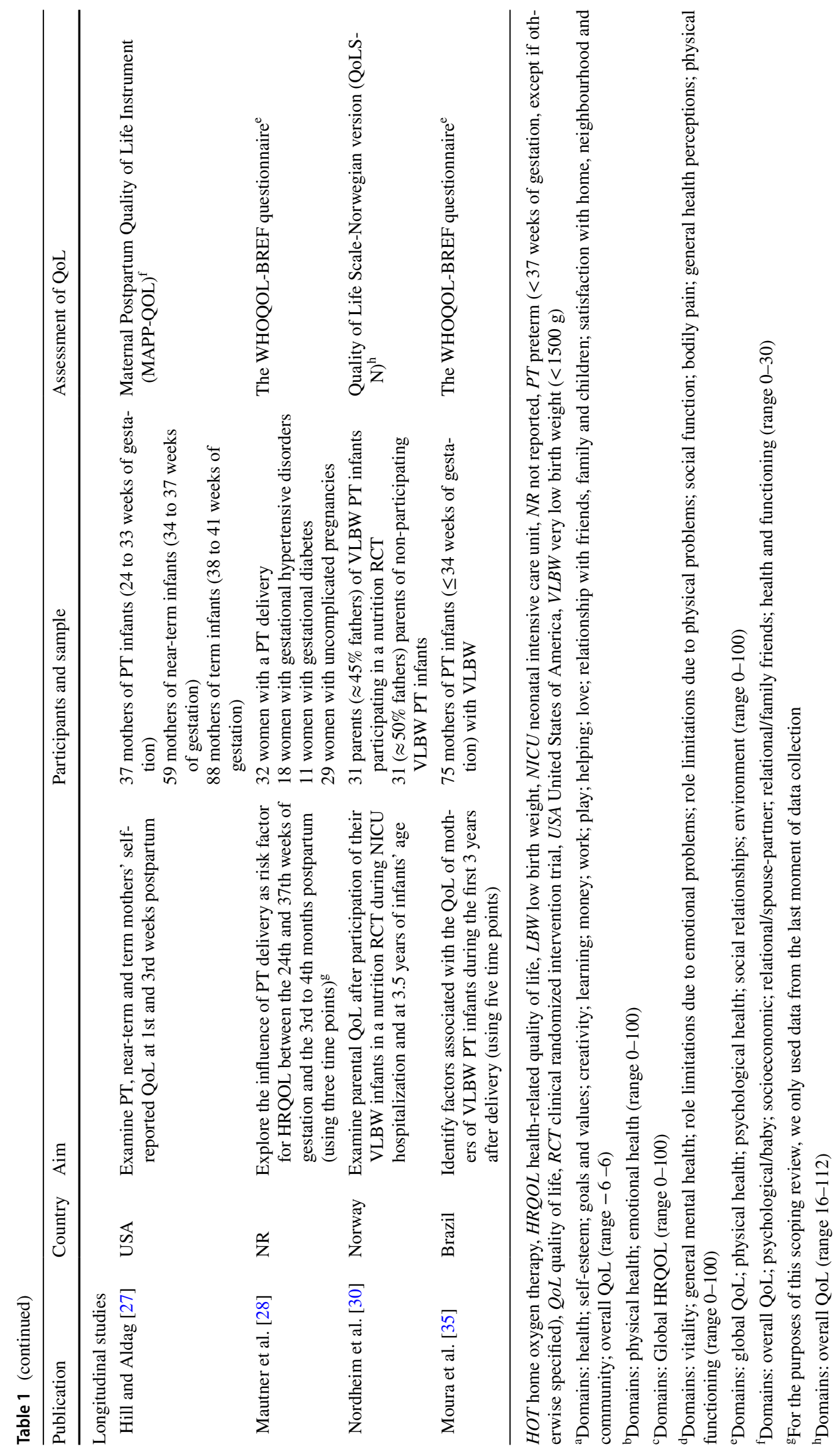


Table 2 Synthesis of the factors whose association with QoL of parents of preterm infants was tested

\begin{tabular}{|c|c|c|c|}
\hline Factors (number of studies) & Negative influence & Positive influence & No association \\
\hline \multicolumn{4}{|l|}{ Mother $(n=8)$} \\
\hline Mental health & $\checkmark \checkmark \checkmark \checkmark^{25,33-35}$ & & $\sqrt{ }^{35}$ \\
\hline Disturbed sleep & $\checkmark \checkmark \checkmark^{32-34}$ & & \\
\hline Fatigue & $\checkmark \checkmark^{33,34}$ & & \\
\hline Stress & $\sqrt{ }^{34}$ & & \\
\hline Pregnancy complications & $\sqrt{ }^{28}$ & & $\sqrt{ }^{35}$ \\
\hline Time postpartum & & $\sqrt{ }^{27}$ & \\
\hline Light exposure & & $\sqrt{ }^{32}$ & \\
\hline Religion & & $\sqrt{ }^{35}$ & \\
\hline Circadian activity rhythms & & & $\checkmark \checkmark^{32,33}$ \\
\hline Parity & & & $\checkmark \checkmark^{26,35}$ \\
\hline Number of miscarriages & & & $\sqrt{ }^{35}$ \\
\hline Night-time total sleep time & & & $\sqrt{ }^{32}$ \\
\hline Self-reported physical health & & & $\sqrt{ }^{25}$ \\
\hline Age & & & $\sqrt{ }^{35}$ \\
\hline Skin colour & & & $\sqrt{ }^{35}$ \\
\hline Educational level & & & $\sqrt{ }^{35}$ \\
\hline Occupation & & & $\sqrt{ }^{35}$ \\
\hline Working status & & & $\sqrt{ }^{26}$ \\
\hline \multicolumn{4}{|l|}{ Infant $(n=7)$} \\
\hline Health problems & $\checkmark \checkmark \checkmark^{23 a, 31,35}$ & & $\checkmark \checkmark^{23 b, 25}$ \\
\hline Gestational age & $\checkmark \checkmark^{27,35}$ & & $\checkmark \checkmark^{26.31}$ \\
\hline Birth weight & & $\sqrt{ }^{25}$ & $\checkmark \checkmark \checkmark^{26,31,35}$ \\
\hline Gender & & $\sqrt{35}$ & $\sqrt{ }^{26}$ \\
\hline Length of stay in NICU & & & $\checkmark \checkmark^{29,35}$ \\
\hline Chronological age & & & $\checkmark \checkmark^{31,35}$ \\
\hline Intrauterine growth restriction & & & $\sqrt{ }^{35}$ \\
\hline APGAR score at $5 \mathrm{~min}$ & & & $\sqrt{ }^{35}$ \\
\hline Motor and language quotient & & & $\sqrt{ }^{25}$ \\
\hline \multicolumn{4}{|l|}{ Family $(n=5)$} \\
\hline Lack/existence of support system & $\sqrt{ }^{23}$ & $\sqrt{ }^{23}$ & \\
\hline Memories of neonatal period (Guilt/Optimism) & $\sqrt{ }^{23}$ & $\sqrt{ }^{23}$ & \\
\hline Relationships to child (spoiled/high appreciation) & $\sqrt{ }^{23}$ & $\sqrt{ }^{23}$ & \\
\hline Presence/absence of impact on parents' lives & $\sqrt{ }^{23}$ & $\sqrt{ }^{23}$ & \\
\hline Changed/not changed plans for future children & $\sqrt{ }^{23}$ & $\sqrt{ }^{23}$ & \\
\hline Family income & $\sqrt{ }^{35}$ & & \\
\hline Stable marital union & & $\sqrt{ }^{35}$ & \\
\hline Family set up & & & $\sqrt{ }^{26}$ \\
\hline Number of adults in home & & & $\sqrt{ }^{25}$ \\
\hline Place of residence & & & $\sqrt{ }^{31}$ \\
\hline \multicolumn{4}{|l|}{ Health care $(n=4)$} \\
\hline Absence/presence of medical information & $\sqrt{ }^{23}$ & $\sqrt{ }^{23}$ & \\
\hline Presence/absence of financial problems & $\sqrt{ }^{23}$ & $\sqrt{ }^{23}$ & \\
\hline Misbehaviour of medical personnel & $\sqrt{ }^{23}$ & & \\
\hline Hospitalization in NICU & $\sqrt{ }^{35}$ & & \\
\hline Participation in a nutrition RCT & & $\sqrt{ }^{30 c}$ & $\sqrt{ }^{30 \mathrm{~d}}$ \\
\hline Mode of delivery & & & $\checkmark \checkmark^{28,35}$ \\
\hline Number of prenatal care visits & & & $\sqrt{ }^{35}$ \\
\hline Use of antenatal corticosteroids & & & $\sqrt{ }^{35}$ \\
\hline
\end{tabular}


Table 2 (continued)

$N I C U$ neonatal intensive care unit, $R C T$ clinical randomized intervention trial

$\checkmark$ Represents the number of studies reporting the respective association

${ }^{a}$ Regarding the dimensions: stress related to the unwillingness of the paediatrician to agree that child had a problem or needed referral for therapy, and difficulties related to the physical work to care for child

${ }^{b}$ Regarding the dimensions: absence of problems with the neonatal hospital bill and the importance given to the support provided by extended family

${ }^{\text {c} D u r i n g ~ i n f a n t ' s ~ h o s p i t a l i z a t i o n ~ i n ~ N I C U ~}$

${ }^{\mathrm{d}}$ At 3.5 years after delivery

\section{Results}

\section{Study characteristics}

\section{Research design}

Six studies were cross-sectional, two were case-control and four were longitudinal studies. Eight of the studies had at least one comparison group, such as caregivers and mothers of full-term infants [25-27], women with other pregnancy complication than a preterm delivery [28], mothers of nearterm (34-37 weeks of gestation) infants [27], parents of very low birth weight (VLBW) infants not participating in a Clinical Randomized Intervention Trial [30], mothers of preterm infants who did not require and previously received home oxygen therapy [31], mothers of infants who did not receive any intensive care or who received special care only for up to a maximum of 3 days [29] and families of neurologically normal infants [23]. The remaining four studies [32-35] assessed the QoL of mothers of preterm infants.

Almost all studies used a quantitative methodology $(n=11)$, assessing QoL through seven different standard instruments. The only mixed methods study relied on interviews using a structured questionnaire and open-ended questions [23]. The timing of data collection ranged from the first to third weeks postpartum during NICU hospitalization [27], until 3 months [28] to 7 years after delivery [23].

\section{Country of study origin and year of publication}

Half of the studies were conducted in the USA, and the remaining derived from 4 countries: Ireland $(n=1)$, Australia $(n=1)$, Norway $(n=1)$ and Brazil $(n=1)$. Two studies did not report the country of study origin, being authored by researchers from India [26] and Austria [28]. The studies were published between 1987 [23] and 2017 [35].

\section{Participants and sample}

In the total of the 12 papers, samples were composed mostly of mothers $(n=9)$, followed by samples of parents $(n=1)$, families $(n=1)$ and primary caregivers $(n=1)$. In the latter,
97.6\% were mothers [25]. The gender of the participants is not specified in the study analysing families [23]. Samples varied from 20 first-time mothers [32] to 223 mothers of late preterm infants [29], and there were 167 caregivers [25], 37 families [23] and 62 parents of VLBW infants [30].

\section{Assessment of QoL}

Half of the studies used the WHOQOL-BREF Questionnaire $[26,28,35]$ or the 36-item Medical Outcomes Short Form36 version 2 [32-34]. The remaining quantitative studies assessed parental QoL through the following instruments: The 36-item Medical Outcomes Short Form (SF36) [31]; Quality of Life Inventory [25]; The PedsQL Family Impact Module [29]; Maternal Postpartum Quality of Life Instrument (MAPP-QOL) [27] and Quality of Life Scale-Norwegian version (QoLS-N) [30]. Five instruments assessed the global/overall QoL [25-30, 35], and three studies measured the domains physical health and emotional health using the same instrument [32-34]. The other 29 QoL domains were evaluated by only one study each $[25,27,31]$. Study by Rivers, Caron and Hack [23] evaluated QoL through the following questions: How has your life been changed by the birth of your premature child?; What has the financial impact of your child's birth been on your family?; How has your child's birth affected your plans for future children?

\section{Factors influencing the QoL of parents of preterm infants}

Factors related with mothers and infants' characteristics were more frequently addressed, followed by those centred on the family and health care. Across all the studies assessed, 45 variables potentially associated with QoL were identified, and in most studies few were considered simultaneously. Only 5 variables were assessed by more than two studies. Inconsistent results were reported concerning four of the five remaining variables: maternal mental health and infant's health problems, gestational age and birth weight. Additionally, the way these variables were measured differed between studies, resulting in inconclusive data. 
Table 3 Main findings of studies on the factors influencing the QoL of parents of preterm infants $(n=12)$

\begin{tabular}{|c|c|}
\hline Factors & Main findings \\
\hline \multicolumn{2}{|l|}{ Mother } \\
\hline Mental health & $\begin{array}{l}\text { Higher EPDS scores: Lower mental maternal HRQOL }(P<0.01)[33,34] \\
\text { Higher median BDI scores: Lower maternal QoL on physical, psychological, social and environmental domains } \\
\quad(P<0.05)[35] \\
\text { Higher Psychiatric Symptoms Index }{ }^{\text {a }} \text { scores: Poor overall maternal QoL }(P<0.001)[25]\end{array}$ \\
\hline Sleep & $\begin{array}{l}\text { More severely disturbed sleep: Lower mental and physical maternal HRQOL }(P<0.05)[32-34] \\
\text { Higher daytime sleepiness: Lower physical and mental maternal HRQOL }(P<0.01)[32,33]\end{array}$ \\
\hline Fatigue & Higher levels of fatigue: Lower physical and mental maternal HRQOL $(P<0.01)[33,34]$ \\
\hline Stress & Higher levels of stress: Lower mental maternal HRQOL $(P<0.01)[34]$ \\
\hline Pregnancy complications & $\begin{array}{l}\text { PT delivery (vs. Gestational hypertensive disorders or Gestational diabetes or. Uncomplicated pregnancy): Lower } \\
\text { maternal QoL on physical domain }(P<0.05)[28]\end{array}$ \\
\hline Time postpartum & Week 3 (vs. Week 1): Higher maternal QoL on health and functioning domain $(P<0.001)$ [27] \\
\hline Light exposure & $\geq 12$ h: Higher physical maternal HRQOL $(P<0.01)[32]$ \\
\hline Religion & Evangelical: Higher maternal QoL on social domain $(P=0.019)[35]$ \\
\hline \multicolumn{2}{|l|}{ Infant } \\
\hline Health problems & $\begin{array}{l}\text { Receiving HOT: Lower maternal QoL on vitality and mental health dimensions }(P<0.05)[31] \\
\text { Posthemorrhagic hydrocephalus: Lower maternal QoL on psychological }(P=0.010) \text { and social domains }(P=0.001) \\
\text { [35] } \\
\text { Bronchopulmonary dysplasia: Lower maternal QoL on physical domain }(P=0.005)[35] \\
\text { Higher score for neonatal acute physiology with perinatal extension: Lower maternal QoL on social domain } \\
(P=0.027) \text { [35] } \\
\text { Cerebral palsy or hydrocephalus (vs. Neurologically normal): More stress related to the unwillingness of the } \\
\text { paediatrician to agree that child had a problem or needed referral for therapy, and more difficulties related to the } \\
\text { physical work to care for child [23] }\end{array}$ \\
\hline Gestational age & $\begin{array}{l}24-33 \text { weeks (vs. 34-37 weeks or 38-41 weeks): Lower maternal QoL on psychological/baby domain }(P<0.001) \\
\text { [27] } \\
\text { Lower number of gestational weeks: Lower maternal QoL on physical domain }(P=0.010)[35]\end{array}$ \\
\hline Birth weight & VLBW (vs. Full-term): Higher overall caregiver's QoL $(P<0.05)[25]$ \\
\hline Gender & Female: Higher maternal QoL on environmental domain $(P=0.011)[35]$ \\
\hline \multicolumn{2}{|l|}{ Family } \\
\hline Support system & $\begin{array}{l}\text { The contact with other parents of preterm children had a positive impact on family QoL, while the lack of support } \\
\text { provided by extended family had a negative impact on family QoL [23] }\end{array}$ \\
\hline Memories of neonatal period & $\begin{array}{l}\text { Religion or optimistic philosophy of life during neonatal period had a positive impact on family QoL, while the } \\
\text { guilt considered as a problem in adjustment influenced negatively the family QoL [23] }\end{array}$ \\
\hline Values and relationships to child & $\begin{array}{l}\text { High appreciation of their child had a positive impact on family QoL, while considering child more "spoiled" or } \\
\text { more protected by parents had a negative impact on family QoL [23] }\end{array}$ \\
\hline Perceived impact on parents' lives & $\begin{array}{l}\text { No much life changes influenced positively family QoL, while the difficulties related to the physical work to care } \\
\text { for child had a negative impact on family QoL [23] }\end{array}$ \\
\hline Plans for future children & $\begin{array}{l}\text { No changes in the plans for future children had a positive impact on family QoL, while the deferral of the birth of } \\
\text { later children or more care with later pregnancy had a negative impact on family QoL [23] }\end{array}$ \\
\hline Family income & BRL 1500-2750 : Lower maternal QoL on environmental domain $(P=0.001)[35]$ \\
\hline Marital union & Stable: Higher maternal QoL on social domain $(P=0.004)[35]$ \\
\hline \multicolumn{2}{|l|}{ Health care } \\
\hline Communication of medical information & $\begin{array}{l}\text { Information and explanation of medical terms by the medical personnel had a positive impact on family QoL dur- } \\
\text { ing neonatal period, and the absence of important medical information had a negative impact on family QoL [23] }\end{array}$ \\
\hline Financial impact & $\begin{array}{l}\text { Do not having problems with the neonatal hospital bill had a positive impact on family QoL, and problems with the } \\
\text { costs of later medical care had a negative impact on family QoL [23] }\end{array}$ \\
\hline Behaviour of medical personnel & Stress due to policy of transporting hospital had a negative impact on family QoL [23] \\
\hline Hospitalization in NICU & $\begin{array}{l}\text { During hospitalization (vs. } 6 \text { months after discharge or } 12 \text { months after discharge): Lower maternal QoL on physi- } \\
\text { cal domain }(P=0.013)[35]\end{array}$ \\
\hline Participation in a nutrition RCT & Enrolled (vs. Not enrolled): Higher parental QoL scores $(P=0.02)$ during infants hospitalization in NICU [30] \\
\hline
\end{tabular}

$B D I$ Beck depression inventory, BRL Brazilian real, EPDS Edinburgh Postnatal Depression Scale, HOT home oxygen therapy, HRQOL healthrelated quality of life, NICU neonatal intensive care unit, $P P$ value, $P T$ preterm, $Q o L$ quality of life, $R C T$ clinical randomized intervention trial, $V L B W$ very low birth weight $(<1500 \mathrm{~g})$

${ }^{a}$ Depression, anxiety, anger and cognitive disturbance

${ }^{\mathrm{b}}$ The equivalent to $406-745 €$ 
Studies reported issues related with the family, the mother and health care as positively influencing parental perception of their own QoL. Having a stable marital union, maintaining contacts with other parents of preterm children, family religious belief or optimistic philosophy of life during the neonatal period, high appreciation of the child and having few changes in life and in plans for having future children, all had a positive impact on parents' QoL [23, 35]. Women experiencing a total light exposure of 12 or more hours per day [32], as well as women self-reporting evangelical religion [35], presented higher levels of perceived physical and social QoL than those who did not. Mothers' perception of QoL on health and functioning domains also improved over time during postpartum period [27]. Parents of preterm infants who participated in a Clinical Randomized Intervention Trial (vs. non-participating) reported significantly higher levels of QoL during hospitalization in NICU [30]. Having no problems with the neonatal hospital bill and receiving information and explanation of medical terms by healthcare professionals also had a positive impact on family QoL [23].

Low levels of QoL were mainly associated with mother-, family- and health care-related factors. Severely disturbed sleep, high levels of daytime sleepiness, fatigue and stress were associated with lower maternal QoL [32-34]. Family issues, such as family income of 1500-2750 Brazilian Reals (406-745 €) [35], lack of support provided by extended family, feelings of guilt considered as a problem in adjustment, the difficult physical work to care for child, considering child more "spoiled" or more protected by parents and the birth of later children deferred or more care with later pregnancy [23], also had a negative impact on QoL. Hospitalization in NICU (vs. 6 or 12 months after discharge) [35], as well as absence of important medical information, stress due to policy of transporting hospital and problems with the financial costs of later medical care, constituted health care-related factors influencing negatively family QoL [23].

The circadian activity rhythms, parity, the number of miscarriages, night-time total sleep time and self-reported physical health, as well as maternal age, skin colour, educational level, occupation and working status, were not associated with maternal QoL [25, 26, 32, 33, 35]. Similarly, the length of infant's stay in NICU, the child's chronological age, the intrauterine growth restriction, the APGAR score at $5 \mathrm{~min}$ and the motor and language quotient were described as factors with no impact on parental QoL [25, 29, 31, 35]. The participation of the infant in a Clinical Randomized Intervention Trial during hospitalization had no impact on parental QoL at 3.5 years after delivery [30]. Finally, the QoL of mothers and fathers of preterm infants was not influenced by the mode of delivery, the number of prenatal care visits and the use of antenatal corticosteroids [28, 35] as well as by the family set up, the number of adults in home and the place of family residence [25, 26, 31].

Studies addressing infant factors related with the presence of health problems, gestational age, birth weight and gender revealed inconsistent results, as well as those assessing maternal mental health and pregnancy complications, which might be explained by differences on assessment tools and timing of data collection. Some studies revealed that higher mother's depression scores [33-35], caregivers' psychiatric symptoms [25] and pregnancy complications [28] were associated with lower QoL, while other reported no association between QoL and self-reported depression/anxiety or pregnancy-related diseases [35]. Having an infant born with 24-33 weeks of gestation (vs. 34-37 or 38-41 weeks), as well as with some health problems (receiving home oxygen therapy, posthemorrhagic hydrocephalus, bronchopulmonary dysplasia, high score for neonatal acute physiology with perinatal extension) was associated with worse maternal QoL [27, 31, 35]. Maternal QoL also tended to decline with the decrease of the number of gestational weeks at birth [35]. In contrast, other studies reported no difference between the QoL of mothers of preterm and full-term infants [26] and no association between infant's gestational age and parental QoL [31]. In addition, parenting an infant with cerebral palsy or hydrocephalus (vs. neurologically normal) revealed to be associated with more stress related to the unwillingness of the paediatrician to agree that the child had a problem or needed therapy and more difficulties related to the physical work to care for child, while had no impact on the problems with the neonatal hospital bill and the importance given to the support provided by extended family [23]. One study showed that the infant's ongoing medical problems were not associated with caregivers' QoL [25]. In addition, one study referred that having a very low birth weight infant (vs. full-term) was positively associated with parental QoL [25], while three other studies reported no association between infant's birth weight and maternal QoL [26, 31, 35]. Finally, one study found that having a female infant (vs. male) had a positive impact on maternal QoL [35], while another one revealed no association between infant's gender and maternal QoL [26].

\section{Discussion}

\section{Current state of research and future direction}

This scoping review suggested that the QoL of parents of preterm infants is mainly influenced by factors related with maternal characteristics, family issues and health care environment rather than aspects related with infants, in a framework where factors from individual fathers and structural levels were not addressed. Studies were based on specific 
sets of variables, for which the assessment varied among studies, with 40 out of 45 factors being analysed by only one or two studies.

Psychosocial characteristics of mothers, namely sleep disturbances, fatigue, stress and poorer mental health (in particular depression and psychiatric symptoms) proved the highest relevance as factors negatively influencing the QoL of mothers of preterm infants. Previous studies conducted during hospitalization in NICU consistently show that parents of preterm infants present high levels of depression, stress and anxiety $[12,14,16,36]$, and report a sense of uncertainty and powerlessness which conjointly impact negatively on parental sleep [37]. Thus, the findings of this scoping review emphasize the need for healthcare professionals to be aware of the impact of a preterm delivery on maternal mental and psychosocial health and sleep patterns during early years. This knowledge will help health professionals to identify groups at risk that should constitute a privileged target for early intervention, aiming to promote parental mental health and improve parents' sleep quality, especially during the first weeks' postpartum. According to our results, future research should explore the maximization of the hours of natural light exposure [32], and the coping strategies related with parents' religion $[23,35]$ as two possible strategies to increase parental QoL.

Five studies addressed family-related variables, but only two found any associations [23, 35]. They described the social support provided by partner, extended family and other parents of preterm children as a factor positively influencing parental mental health and QoL, reinforcing the importance of the support system also reported by parents of full-term infants [38-41]. At the same time, results coherently showed that parental QoL benefits from the fact that parents did not perceive a preterm delivery as a disruptive event for the family. In a context where a preterm delivery constitutes a risk factor for recurrence in subsequent pregnancies [42], parents tended to change their plans for reproductive trajectories when their first pregnancy ended with a preterm delivery [43], which may have a negative impact on family QoL. These findings call for the need to explore in depth the role of several coping strategies to handle adversity and to deal with a preterm delivery [44, 45] as a factor influencing positively parental and family QoL. Furthermore, there is room to explore the influence of other family-related factors on QoL of parents of preterm infants, including those which were addressed by only one study (e.g. family set up, number of adults at home and place of family residence).

Only four studies reported issues related with health care $[23,28,30,35]$. The way medical information is communicated and the degree of parental concern with financial costs of medical care constituted two main factors related with health care environment influencing parental QoL. These results suggest that health professionals' acknowledgement of parental needs for information, financial support and assurance [46] when dealing with mothers and fathers of preterm infants is central to the development of integrated, sustainable and quality family-centred health care services. This review also highlights the importance of further exploring the impact of medical insurance and family income on parental QoL, in a context where caregivers/families of infants with physical and mental illness reported better QoL when having a public insurance $[40,41]$ and parents of preterm infants reported less emotional burden when they have financial compensation for time taken off from work [47].

Studies performed with parents of infants with chronic diseases also suggest that other variables than infant-related factors influence the QoL of mothers and fathers, in particular factors related with characteristics of mothers and fathers and health care environment $[41,48,49]$. However, some of these factors were not tested by most of the studies included in this scoping review, namely those associated with parents' self-efficacy and coping strategies [41, 50], maternal and paternal educational level [51] and employment status [52], family socioeconomic status [51], quality of the marital relation [40], parental health-related behaviours such as eating habits and exercise [49], use of community-based developmental resources (e.g. early intervention programs) [47] and regulation of parental leave [48]. The assessment of these variables in future research will contribute to a better understanding of QoL of parents of preterm infants.

\section{Methodological features}

There are some methodological limitations in the studies included in this scoping review that should be taken into account when analysing the results. A considerable heterogeneity across the studies was observed regarding the operationalization of QoL and the use of different units of analysis (mothers, parents, families and caregivers). Additionally, a small number of studies conducted in few countries and specific settings, with different periods of data collection, are available.

QoL, as defined by WHO [20], has been subjected to several interpretations. Only two studies presented a definition of QoL [25, 27], and the remaining used interchangeably concepts as health-related QoL, life satisfaction, parental functioning and well-being as proxies of QoL [28-30, 35]. This translates into the use of seven different quantitative instruments to measure the construct, which assessed specific domains and proxies of QoL. The presented findings can thus be biased by the different measures used to assess QoL [29, 32-34, 53].

In the last four decades, condition-specific QoL questionnaires have been developed for caregivers of infants with several medical conditions, aiming to assess the specific 
impact of each condition on caregivers' QoL [54]. However, no specific tool has been designed to assess QoL of parents of preterm infants. Although the failures of the available quantitative instruments were acknowledged in one study [26], no attempts were observed to explore whether there are dimensions or constructs specifically relevant for parents of preterm infants not addressed in the questionnaires. As pointed out in this scoping review, parents bring up some dimensions influencing their own QoL that differ from those covered by the quantitative instruments, namely the importance of the support system, the information needs and the medical, reproductive and social costs related with a preterm delivery. These findings call for the development of more mixed methods studies, which would lead to a wider understanding of the QoL of parents of preterm infants [55], assisting us to disentangle the mechanisms behind some contradictory findings, and to the identification of the issues that are missing from the available scales by involving different stakeholders (e.g. parents, health professionals and relevant community stakeholders) [53].

Finally, more detailed data about the QoL of fathers of preterm infants are required. It could serve as a basis for exploring if parenthood is more consistently linked to wellbeing among men than women [56]. Although fatherhood has been associated with greater life satisfaction, happiness, positive affect and less with depressive symptoms [57-59], literature suggested that fathers of preterm infants, similarly to mothers, experienced high rates of psychological distress after birth due to the simultaneously concern for the hospitalized infant, providing support to the mother, communicating with family and friends, caring for other infants and returning to work $[12,14,60]$.

\section{Conclusion}

The aim of this scoping review was to synthesize the current body of knowledge on the factors influencing the QoL of mothers and fathers of preterm infants. Studies addressed mainly mother- and infant-related factors. The results suggested that parental QoL after a preterm delivery is mainly influenced by factors related with mother's characteristics, family issues and health care environment rather than infants' variables, in a context where factors regarding fathers' characteristics and structural levels were not addressed. There is a need for standardizing the operationalization of the QoL and developing a structured questionnaire adapted to the specific needs of mothers and fathers of preterm infants. Further research on parental QoL after a preterm delivery should include both mothers and fathers, invest in mixed methods approaches and be performed in different countries and settings for allowing integration and comparison of findings.

Funding This work was supported by FEDER funding from the Operational Programme Factors of Competitiveness-COMPETE and by national funding from the Foundation for Science and Technology-FCT (Portuguese Ministry of Science, Technology and Higher Education) under the project "Parenting roles and knowledge in Neonatal Intensive Care Units" (FCOMP-01-0124-FEDER-019902; Ref. FCT PTDC/CS-ECS/120750/2010) and the Unidade de Investigação em Epidemiologia-Instituto de Saúde Pública da Universidade do Porto (EPIUnit) (POCI-01-0145-FEDER-006862; Ref. UID/ DTP/04750/2013); the grants PD/BD/105830/2014 (to MA), SFRH/ BPD/103562/2014 (to EA), co-funded by the FCT and the POPH/FSE Program and the FCT Investigator contract IF/01674/2015 (to SS).

\section{Compliance with ethical standards}

Conflict of interest The authors declare that they have no conflict of interest.

Ethical approval This article does not contain any studies with human participants or animals performed by any of the authors.

\section{References}

1. World Health Organization. (2012). Born too soon: the global action report on preterm birth. Geneva: WHO Press.

2. Wang, H., Bhutta, Z. A., Coates, M. M., Coggeshall, M., Dandona, L., Diallo, K., Franca, E. B., Fraser, M., Fullman, N., Gething, P. W., et al. (2016). Global, regional, national, and selected subnational levels of stillbirths, neonatal, infant, and under-5 mortality, 1980-2015: A systematic analysis for the Global Burden of Disease Study 2015. The Lancet, 388(10053), 1725-1774.

3. Blencowe, H., Cousens, S., Oestergaard, M. Z., Chou, D., Moller, A. B., Narwal, R., Adler, A., Garcia, V., Rohde, C., Say, S., L., \& Lawn, J. E. (2012). National, regional, and worldwide estimates of preterm birth rates in the year 2010 with time trends since 1990 for selected countries: a systematic analysis and implications. The Lancet, 379(9832), 2162-2172.

4. McCormick, M. C., Litt, J. S., Smith, V. C., \& Zupancic, J. A (2011). Prematurity: An overview and public health implications. Annual Review of Public Health, 32, 367-379.

5. Vieira, M. E., \& Linhares, M. B. (2016). Quality of life of individuals born preterm: A systematic review of assessment approaches. Quality of Life Research, 25(9), 2123-2139.

6. Zeitlin, J., Manktelow, B. N., Piedvache, A., Cuttini, M., Boyle, E., van Heijst, A., Gadzinowski, J., Van Reempts, P., Huusom, L., Weber, T., Schmidt, S., Barros, H., Dillalo, D., Toome, L., Norman, M., Blondel, B., Bonet, M., Draper, E. S., \& Maier, R. F. (2016). Use of evidence based practices to improve survival without severe morbidity for very preterm infants: results from the EPICE population based cohort. BMJ, 354, i2976.

7. EPICE. (2017). Effective perinatal intensive care in Europe: Translating knowledge into evidence-based practice. Retrieved December 11, 2017 from http://www.epiceproject.eu/en/.html.

8. Milligan, D. W. (2010). Outcomes of children born very preterm in Europe. Archives of Disease in Childhood Fetal and Neonatal Edition, 95(4), F234-F240.

9. O'Brien, K., Bracht, M., MacDonell, K., McBride, T., Robson, K., \& O’Leary, L. (2013). A pilot cohort analytic study of family 
integrated care in a Canadian neonatal intensive care unit. $B M C$ Pregnancy and Childbirth, 13(Suppl 1), S12.

10. Alves, E., Amorim, M., Fraga, S., Barros, H., \& Silva, S. (2014). Parenting roles and knowledge in neonatal intensive care units: Protocol of a mixed methods study. British Medical Journal Open, 4(7), e005941.

11. Treyvaud, K., Anderson, V. A., Lee, K. J., Woodward, L. J., Newnham, C., Inder, T. E., Doyle, L. W., \& Anderson, P. J. (2010). Parental mental health and early social-emotional development of children born very preterm. Journal of Pediatric Psychology, 35(7), 768-777.

12. Baia, I., Amorim, M., Silva, S., Kelly-Irving, M., de Freitas, C., \& Alves, E. (2016). Parenting very preterm infants and stress in Neonatal Intensive Care Units. Early Human Development, 101, 3-9.

13. Forcada-Guex, M., Borghini, A., Pierrehumbert, B., Ansermet, F., \& Muller-Nix, C. (2011). Prematurity, maternal posttraumatic stress and consequences on the mother-infant relationship. Early Human Development, 87(1), 21-26.

14. Koliouli, F., Gaudron, C. Z., \& Raynaud, J-P. (2016). Stress, coping, and post-traumatic stress disorder of French fathers of premature infants. Newborn and Infant Nursing Reviews, 16(3), 110-114.

15. Garel, M., Bahuaud, M., \& Blondel, B. (2004). [Consequences for the family of a very preterm birth two months after discharge. Results of the EPIPAGE qualitative study]. Archives de Pédiatrie, 11(11), 1299-1307.

16. Vigod, S. N., Villegas, L., Dennis, C. L., \& Ross, L. E. (2010). Prevalence and risk factors for postpartum depression among women with preterm and low-birth-weight infants: A systematic review. BJOG, 117(5), 540-550.

17. Treyvaud, K., Doyle, L. W., Lee, K. J., Roberts, G., Cheong, J. L., Inder, T. E., \& Anderson, P. J. (2011). Family functioning, burden and parenting stress 2 years after very preterm birth. Early Human Development, 87(6), 427-431.

18. Treyvaud, K. (2014). Parent and family outcomes following very preterm or very low birth weight birth: A review. Seminars in Fetal and Neonatal Medicine, 19(2), 131-135.

19. Konstantyner, T., Leite, H. P., \& Taddei, A. C. (2007). Effects of a very low birth weight newborn on family: Literature review. Nutrición Hospitalaria, 22(2), 138-145.

20. WHOQOL Group. (1994). Development of the WHOQOL: Rationale and current status. International Journal of Mental Health, 23(3), 24-56.

21. Levac, D., Colquhoun, H., \& O'Brien, K. K. (2010). Scoping studies: advancing the methodology. Implementation Science, 5,69 .

22. Arksey, H., \& O’Malley, L. (2005). Scoping studies: Towards a methodological framework. International Journal of Social Research Methodology, 8(1), 19-32.

23. Rivers, A., Caron, B., \& Hack, M. (1987). Experience of families with very low birthweight children with neurologic sequelae. Clinical Pediatrics, 26(5), 223-230.

24. Stemler, S. (2001). An overview of content analysis. Practical Assessment, Research and Evaluation, 7(17), 137-146.

25. Donohue, P. K., Maurin, E., Kimzey, L., Allen, M. C., \& Strobino, D. (2008). Quality of life of caregivers of very lowbirthweight infants. Birth, 35(3), 212-219.

26. Sharma, M., \& Sohi, I. (2007). Quality of life of mothers of preterm and term babies. Journal of Neonatology, 21(4), 281-284.

27. Hill, P. D., \& Aldag, J. C. (2007). Maternal perceived quality of life following childbirth. Journal of Obstetric, Gynecologic and Neonatal Nursing, 36(4), 328-334.

28. Mautner, E., Greimel, E., Trutnovsky, G., Daghofer, F., Egger, J. W., \& Lang, U. (2009). Quality of life outcomes in pregnancy and postpartum complicated by hypertensive disorders, gestational diabetes, and preterm birth. Journal of Psychosomatic Obstetrics and Gynecology, 30(4), 231-237.

29. McGowan, J. E., Alderdice, F. A., Boylan, J., Holmes, V. A., Jenkins, J., Craig, S., Perra, O., \& Johnston, L. (2014). Neonatal intensive care and late preterm infants: Health and family functioning at three years. Early Human Development, 90(4), 201-205.

30. Nordheim, T., Rustoen, T., Iversen, P. O., \& Nakstad, B. (2016). Quality of life in parents of preterm infants in a randomized nutritional intervention trial. Food and Nutrition Research, 60 , 32162

31. McLean, A., Townsend, A., Clark, J., Sawyer, M. G., Baghurst, P., Haslam, R., \& Whaites, L. (2000). Quality of life of mothers and families caring for preterm infants requiring home oxygen therapy: A brief report. Journal of Paediatrics and Child Health, 36(5), 440-444

32. Lee, S. Y., \& Kimble, L. P. (2009). Impaired sleep and well-being in mothers with low-birth-weight infants. Journal of Obstetric, Gynecologic and Neonatal Nursing, 38(6), 676-685.

33. Lee, S. Y., Grantham, C. H., Shelton, S., \& Meaney-Delman, D. (2012). Does activity matter: An exploratory study among mothers with preterm infants? Archives of Women's Mental Health, 15(3), 185-192.

34. Lee, S. Y., \& Hsu, H. C. (2012). Stress and health-related wellbeing among mothers with a low birth weight infant: The role of sleep. Social Science and Medicine, 74(7), 958-965.

35. Moura, M. R., Araujo, C. G., Prado, M. M., Paro, H. B., Pinto, R. M., Abdallah, V. O., Mendonca, T. M., \& Silva, C. H. (2017). Factors associated with the quality of life of mothers of preterm infants with very low birth weight: A 3-year follow-up study. Quality of Life Research, 26(5), 1349-1360.

36. Ionio, C., Colombo, C., Brazzoduro, V., Mascheroni, E., Confalonieri, E., Castoldi, F., \& Lista, G. (2016). Mothers and fathers in NICU: The impact of preterm birth on parental distress. Europe's Journal of Psychology, 12(4), 604-621.

37. Edell-Gustafsson, U., Angelhoff, C., Johnsson, E., Karlsson, J., \& Morelius, E. (2015). Hindering and buffering factors for parental sleep in neonatal care. A phenomenographic study. Journal of Clinical Nursing, 24(5-6), 717-727.

38. Emmanuel, E., St. John, W., \& Sun, J. (2012). Relationship between social support and quality of life in childbearing women during the perinatal period. Journal of Obstetric, Gynecologic and Neonatal Nursing, 41(6), E62-E70.

39. Webster, J., Nicholas, C., Velacott, C., Cridland, N., \& Fawcett, L. (2011). Quality of life and depression following childbirth: impact of social support. Midwifery, 27(5), 745-749.

40. Bidzan, M., \& Bieleninik, L. (2013). Conditions of the quality of life and life satisfaction of mothers of preterm babies in Poland. Journal of Socialomics, 2(2), e117.

41. Guillamon, N., Nieto, R., Pousada, M., Redolar, D., Munoz, E., Hernandez, E., Boixados, M., \& Gomez-Zuniga, B. (2013). Quality of life and mental health among parents of children with cerebral palsy: The influence of self-efficacy and coping strategies. Journal of Clinical Nursing, 22(11-12), 1579-1590.

42. Phillips, C., Velji, Z., Hanly, C., \& Metcalfe, A. (2017). Risk of recurrent spontaneous preterm birth: A systematic review and meta-analysis. British Medical Journal Open, 7(6), e015402.

43. Newman, L. (2008). How parenthood experiences influence desire for more children in Australia: A qualitative study. Journal of Population Research, 25(1), 1-27.

44. Lou, H., Pedersen, B. D., \& Hedegaard, M. (2009). Questions never asked. Positive family outcomes of extremely premature childbirth. Quality of Life Research, 18(5), 567-573.

45. Alves, E., Amorim, M., Baía, I., \& Silva, S. (2017). Parents' perspectives on the hospitalization of preterm infants in Neonatal Intensive Care Units: A literature review. In E. Sanders (Ed.), 
Neonatal intensive care: Issues, insights and studies (pp. 37-97). New York: Nova Biomedical.

46. Ward, K. (2001). Perceived needs of parents of critically ill infants in a neonatal intensive care unit (NICU). Pediatric Nursing, 27(3), 281-286.

47. Lakshmanan, A., Agni, M., Lieu, T., Fleegler, E., Kipke, M., Friedlich, P. S., McCormick, M. C., \& Belfort, M. B. (2017). The impact of preterm birth $<37$ weeks on parents and families: A cross-sectional study in the 2 years after discharge from the neonatal intensive care unit. Health and Quality of Life Outcomes, 15(1), 38

48. Lawoko, S., \& Soares, J. J. (2003). Quality of life among parents of children with congenital heart disease, parents of children with other diseases and parents of healthy children. Quality of Life Research, 12(6), 655-666.

49. Klassen, A. F., Klaassen, R., Dix, D., Pritchard, S., Yanofsky, R., O'Donnell, M., Scott, A., \& Sung, L. (2008). Impact of caring for a child with cancer on parents' health-related quality of life. Journal of Clinical Oncology, 26(36), 5884-5889.

50. Ganjiwale, D., Ganjiwale, J., Sharma, B., \& Mishra, B. (2016). Quality of life and coping strategies of caregivers of children with physical and mental disabilities. Journal of Family Medicine and Primary Care, 5(2), 343-348.

51. Misura, A. K., \& Memisevic, H. (2017). Quality of life of parents of children with intellectual disabilities in Croatia. Journal of Educational and Social Research, 7(2), 43-48.

52. Ahmadizadeh, Z., Rassafiani, M., Amozadeh Khalili, M., \& Mirmohammadkhani, M. (2015). Factors associated with quality of life in mothers of children with cerebral palsy in Iran. Hong Kong Journal of Occupational Therapy, 25, 15-22.
53. Mogos, M. F., August, E. M., Salinas-Miranda, A. A., Sultan, D. H., \& Salihu, H. M. (2013). A systematic review of quality of life measures in pregnant and postpartum mothers. Applied Research in Quality of Life, 8(2), 219-250.

54. Chow, M. Y. K., Morrow, A. M., Cooper Robbins, S. C., \& Leask, J. (2013). Condition-specific quality of life questionnaires for caregivers of children with pediatric conditions: A systematic review. Quality of Life Research, 22(8), 2183-2200.

55. Creswell, J. W. (2015). A concise introduction to mixed methods research. Thousand Oaks: Sage Publications, Inc.

56. Nelson, S. K., Kushlev, K., \& Lyubomirsky, S. (2014). The pains and pleasures of parenting: When, why, and how is parenthood associated with more or less well-being? Psychological Bulletin, 140(3), 846-895.

57. Hansen, T., Slagsvold, B., \& Moum, T. (2009). Childlessness and psychological well-being in midlife and old age: An examination of parental status effects across a range of outcomes. Social Indicators Research, 94(2), 343-362.

58. Keizer, R., Dykstra, P. A., \& Poortman, A-R. (2010). Life outcomes of childless men and fathers. European Sociological Review, 26(1), 1-15.

59. Nelson, S. K., Kushlev, K., English, T., Dunn, E. W., \& Lyubomirsky, S. (2013). In defense of parenthood: Children are associated with more joy than misery. Psychological Science, 24(1), 3-10.

60. Mackley, A. B., Locke, R. G., Spear, M. L., \& Joseph, R. (2010). Forgotten parent: NICU paternal emotional response. Advances in Neonatal Care, 10(4), 200-203. 